\title{
Study of anemia types in the blood parameters among children of Baqubah city Amjad Adham Ahmed(MSc) ${ }^{1}$ and Hameed Mahmood Majeed $(\mathrm{PhD})^{2}$
}

\begin{abstract}
Background: Anemia is the most common condition in blood diseases, is caused by a decrease in hemoglobin concentration on normal level .

Objective:To the increased prevalence of anemia among children and women and The Purpose of recognize the types of anemia among children in Ba'qubah and How to diagnose and reduce the prevalence of anemia among children.
\end{abstract}

Patients and Methods: This study was conducted in the Al-Batoul pediatric Hospital of Diyala Health Department for the duration of the first of October and ends on the 31st of December of the year 2016, which collect 383 ( 212 male 55\%, 171 female $45 \%$ ) blood samples of children sick Anemic ( Hemoglobin levels less than $11.0 \mathrm{~g} / \mathrm{DL}$ ) with age range between 1-15 years, with $2.5 \mathrm{~cm} 3$ venous blood into a tube containing (EDTA) Ethylene diamine tetra acetic acid for blood picture, adopting the mean corpuscular volume (MCV) in classification anemia MCV $<80 \mathrm{fl}, \mathrm{MCV}=80-100 \mathrm{fl}, \mathrm{MCV}>100 \mathrm{fl}$, as a bloody tinge to help with microscopy .

Results: The results of the current study showed that most anemic patients samples was of mean corpuscular volume for less $80 \mathrm{fl}$, represented by iron deficiency anemia by $45.69 \%$ and Thalassemia by $38.12 \%$. While the mean corpuscular volume range between MCV $=80-100 \mathrm{fl}$ ratio $13.05 \%$ spread on the sickle by $4.96 \%$ and Spherocytosis anemia by $8.09 \%$, while the mean corpuscular volume for more than $100 \mathrm{fl}$ at ratio low 3.13\% and represented by vitamin B12 anemia, which showed the latter strongest decrease in numbers of red blood cells and hemoglobin level, And this decrease in numbers of red blood cells and hemoglobin level was strongest in the Thalassemia and sickle cell anemia, compared by iron deficiency anemia, and Spherocytosis anemia, while decrease mean corpuscular hemoglobin in iron deficiency anemia and Thalassemia and increase in Vitamin B12 deficiency anemia. As the study indicated that the numbers of white blood cells exceeded the normal in patients with Thalassemia and vitamin B12 deficiency anemia .

Conclusion:The present study concludes that there is strongest decrease in numbers of red blood cells and hemoglobin in patients with hemolytic anemia and lack vitamin B12 with very high numbers of white blood cells.

Key words: Anemia, Hemoglobin, Red blood cell .

Corresponding Author: amjadadh@gmail.com

Received: $16^{\text {th }}$ October 2017

Accepted: $14^{\text {th }}$ November 2017

https://doi.org/10.26505/DJM

${ }^{1,2}$ Department of Biology - College of Education for Pure Science - Diyala University - Diyala - Iraq.

\section{Introduction}

Anemia is a decrease in blood to transfer a tissues because of the low level of sufficient amount of oxygen to various body hemoglobin in red blood cells or a decrease 
in the total number of red blood cells in the circulatory system, and on this basis the tissue does not receive enough oxygen to grow and sustain their various activities [1]. It is the most common condition in hematology and is one of the most common health problems in the world and one of the important clinical signs of underlying disorders. Unlike the prevalence of anemia among preschool children, especially between 6 months and 5 years, $80 \%$ of which affects children before school age and pregnant women in developing countries, and $20 \%$ of children in the United States, at least $30-40 \%$ in industrialized countries [2]. In Iraq an increase was observed in the incidence of anemia to different segments of society as a result of the economic situation and the severe lack of nutrients in addition to some wrong food habits and other effects that will have a bad effect on normal rates for the blood of each individual in Iraq which has led to an increase in the incidence of anemia in the Iraqi society [3].

There are many factors that play a role in the etiology of anemia such as socio-economic and nutritional, biological, environmental and cultural properties [4].It is believed that the most anticipated causes for anemia is the decline in the production of red blood cells or blood loss. These factors result from a lack of essential elements like iron, vitamin B12, folic acid, or may produce a few basic elements of food shortage, malabsorption, bleeding disorders or idle bone marrow, hormone deficiency, chronic diseases or infections that lead to lower production, and hemolytic anemia which is associated with increased cells crash [5].

\section{Patients and Methods}

Venous blood samples were obtained from children at Al-Batoul pediatric Hospital in Ba'qubah for the from the laboratory section (blood draw) on a daily basis from 8:30 a.m. to 2 p.m., from October 1st. Until the 31st of December of the year 2016, 383 blood samples were obtained (212 male $55 \%$ and 171 female $45 \%$ ), where the venous blood was placed in 2.5 liter tubes containing clot blocker (EDTA) ( Ethylene diamine tetra acetic acid). Used directly without storing to take blood picture. After you mix it gently on my blending Vortex-type Mixer samples, then put on your DX Pentra ABX 120 blood analyses for total Complete blood counts (CBC) containing the measure of hemoglobin concentration $(\mathrm{Hb})$, haematocrit $(\mathrm{Hct})$, and acount of numbers of red blood cells (RBCs), mean corpuscular volume (MCV), mean corpuscular hemoglobin $(\mathrm{MCH})$, mean corpuscular hemoglobin concentration (MCHC), and acount of numbers of white blood cells ( WBCs) and acount of numbers of platelets ( PLT ).)Then the same sample was used to make blood smear on a glass slide. As a special form was prepared for each patient including date of birth, sex, history, blood type and treatment. Hemoglobin concentration adopted under par (less than $11 \mathrm{~g} / \mathrm{DL}$ ) allowed according to the World Health Organization to diagnose the presence of Anemia [6]. Depending on the count and bloody measure mean corpuscular volume (MCV), and the shape and size of red 
blood cells that appear in the blood swab under a microscope to diagnose types of anemia .

Blood Film:Blood film is a thin layer of blood erased or smudged on a glass slide to see the components of blood (white blood cells, red blood cells, and platelets). blood film from blood testing task is used extensively in laboratories because of its great importance in the diagnosis of anemia [7].

\section{Procedure}

1-Put the glass slide on the surface level, take a drop of blood from the blood tube containing EDTA blood Pipettes brokered and put on one of the edges specifically slide 1-2 $\mathrm{mm}$ distance from the edge so that the moderate drop be neither small nor large.

2- I caught the second slide in my hand between the forefinger and thumb and placed it in front of the blood drop with a sharp corner, then take it back to touch the blood drop, blood will spread on the edge of the slide and then push the roll forward quickly and with a fixed angle without interruption.

3- Blood smear is left to dry in a place with a special number level slide for each patient.

staining of blood smear:Put the slide containing the blood smear on the special holder above the sink in the lab. The slide is covered entirely with shorthand and left for 10 minutes Until they change color and then wash the slide with tap water and leave it to dry. We have finished preparing the blood swab [7].

The slide is examined using oily lens (100X) for the purpose of diagnosing types of anemia that exist through the emergence of differing in shape and size of red blood cells in the smear staining as follows :

1-People in iron deficiency anemia blood swab under a microscope, where red blood cells are small size hypopigmented and microcytic cells look pretty grim episode in the ocean and pale and colorless, and pale and colorless Center further demonstrates a lack of pigment .

2- Vitamin B12 deficiency anemia is diagnosed in person and folic acid in the blood swab under a microscope where the red blood cells larger than usual size macrocytic with increased pigment and red aromats were seen and weadlat oval red blood cells trailing altvses.

3- Thalassemia anemia is diagnosed in blood swab under a microscope, where red blood cells are compact hypopigmented microcytic with different forms of red blood cells and red blood cells with a size two targets Target cells and red blood cells in a drop of tears Tear Drop and parts of red blood cells. Fragmented cell.

4- sickle cell in blood swab is diagnosed under a microscope, where red blood cells lose natural ring form to a visible Crescent cell and Sickle cells resemble a canoe and shrunken cells are irregular.

5- Spherocytes anemia is diagnosed in wipe under a microscope, where red blood cells lose their natural ring shape and become spherical in shape (balled) dark Spherocytes [8]. 


\section{Statistical Analysis}

Statistical analysis was performed using random design) (C.R.D. Factorial Experiment with global experience working, either factoral differences between test coefficients Duncan test used the polynomial's Duncan multiple range test [9] use statistical analysis software S.A.S-drink (2010) for data analysis [10].

\section{Results}

Table number (1) shows that there are 321 $(83.81 \%)$ of the blood samples, mean corpuscular volume less than $\mathrm{MCV}<80 \mathrm{fl}$ of with 175 sample percentage (45.69\%) including samples iron deficiency anemia, decreased levels of hemoglobin concentration, haematocrit , mean corpuscular hemoglobin, to reach $10.15 \pm$ $0.10 \mathrm{~g} / \mathrm{dl}, 33.35 \pm 0.33 \%, 22.07 \pm 0.27 \mathrm{pg}$ respectively, note that the numbers of red blood cells were within normal average .

Including sample and $146(38.12 \%)$ blood sample belonging to thalassemia, decreased hemoglobin levels, red blood cells numbers, haematocrit to reach $7.33 \pm 0.10 \mathrm{~g} / \mathrm{dl}, 3.03 \pm$ 0.04 cells/microliter $\times 106,24.42 \pm 0.30 \%$ respectively.

As for the white blood cells, they were more than the normal level, averaged over $(15.93 \pm$ $0.71)$ cell/microliter $\times 103$.
Table (1) shows that 50 sample (13.05\%), mean corpuscular volume between $\mathrm{MCV}=$ 80-100 fl to which 19 sample percentage (4.96\%) due to sickle cell anemia, decreased levels of hemoglobin concentration, red blood cell numbers, haematocrit to reach 8.67 $\pm 10.4 \mathrm{~g} / \mathrm{dl}, 3.15 \pm 0.15 \mathrm{cell} /$ microliter $\times 103$, $28.10 \pm 1.40 \%$ respectively. As for the white blood cells they exceeded the normal average $11.80 \pm 1.86$ cell/microliter x 103 .

Including sample and $31(8.09 \%)$ samples of anemia due to anemia balled erythrocytes, noting that the numbers of red blood cells within normal levels, with an average of 4.03 \pm 0.09 cell $/$ microliter $\times 106$, and with decreased in the mean corpuscular hemoglobin, mean corpuscular hemoglobin concentration, Which affected the overall hemoglobin levels , to reach $27.10 \pm 0.51 \mathrm{pg}$ , $30.41 \pm 0.43 \mathrm{~g} / \mathrm{dl}, 10.82 \pm 0.16 \mathrm{~g} / \mathrm{dl}$, respectively. As for the white blood cells, they exceeded the natural rate, averaged $11.30 \pm 1.04 \mathrm{cell} /$ microliter x 103 .

Table (1) shows that 12 sample percentage $(3.13 \%)$ of the blood samples of 383 belonging to B12 vitamin deficiency anemia, decreased blood levels of both mean corpuscular hemoglobin, red blood cell numbers, haematocrit to reach $8.83 \pm 0.64$ $\mathrm{g} / \mathrm{dl}, 2.83 \pm 0.24 \mathrm{cell} /$ microliter $\times 106,28.86$ $\pm 2.35 \%$ Respectively. 
Table (1): Classification of anemia due to the mean corpuscular volume.

\begin{tabular}{|c|c|c|c|c|c|}
\hline $\mathrm{MCV}$ & \multicolumn{2}{|c|}{$\mathrm{MCV}<80 \mathrm{FL}$} & \multicolumn{2}{|c|}{$\mathrm{MCV}=80-100 \mathrm{fL}$} & $\mathrm{MCV}>100 \mathrm{fL}$ \\
\hline Numbers & \multicolumn{2}{|c|}{ (\% 83.81) 321} & \multicolumn{2}{|c|}{$(\%$ (\% 13.05$) 50$} & (\% 3.13 ) 12 \\
\hline & $\begin{array}{c}\text { Iron-deficiency } \\
\text { anemia }\end{array}$ & Thalassemia & Sickle cell anemia & Spherocytosis & $\begin{array}{c}\text { Deficiency } \\
\text { Vitamin B12 }\end{array}$ \\
\hline & $(\% 45.69) 175$ & $(\% 38.12) 146$ & $(\% 4.96) 19$ & $(\% 8.09) 31$ & $(\% 3.13) 12$ \\
\hline Variables & Mean \pm SE & Mean \pm SE & Mean \pm SE & Mean \pm SE & Mean \pm SE \\
\hline $\mathrm{Hb}(\mathrm{g} / \mathrm{dl})$ & $\begin{array}{c}10.15 \pm 0.10 \\
a\end{array}$ & $\begin{array}{c}7.33 \pm 0.10 \\
C\end{array}$ & $\begin{array}{c}8.67 \pm 0.41 \\
b\end{array}$ & $\begin{array}{c}10.82 \pm 0.16 \\
a\end{array}$ & $\begin{array}{c}8.83 \pm 0.64 \\
b\end{array}$ \\
\hline $\operatorname{RBC}\left(10^{6} / \mathrm{m} \mathrm{m}^{3}\right)$ & $\begin{array}{c}4.66 \pm 0.04 \\
\mathrm{a}\end{array}$ & $\begin{array}{c}.03 \pm 0.04 \\
\mathrm{Cd}\end{array}$ & $\begin{array}{c}.15 \pm 0.15 \\
\mathrm{c}\end{array}$ & $\begin{array}{c}4.03 \pm 0.09 \\
b\end{array}$ & $\begin{array}{c}2.83 \pm 0.24 \\
\mathrm{~d}\end{array}$ \\
\hline $\operatorname{Htc}(\%)$ & $\begin{array}{c}33.35 \pm 0.33 \\
b\end{array}$ & $\begin{array}{c}24.42 \pm 0.30 \\
D\end{array}$ & $\begin{array}{c}28.10 \pm 1.40 \\
\mathrm{c}\end{array}$ & $\begin{array}{c}35.79 \pm 0.72 \\
\text { a }\end{array}$ & $\begin{array}{c}28.86 \pm 2.35 \\
c\end{array}$ \\
\hline $\mathrm{MCH}(\mathrm{pg})$ & $\begin{array}{c}22.07 \pm 0.27 \\
\mathrm{~d}\end{array}$ & $\begin{array}{c}25.52 \pm 0.18 \\
c\end{array}$ & $\begin{array}{c}27.65 \pm 0.62 \\
b\end{array}$ & $\begin{array}{c}27.10 \pm 0.51 \\
b\end{array}$ & $\begin{array}{c}32.93 \pm 0.71 \\
\mathrm{a}\end{array}$ \\
\hline "MCHC ( g/ dl ) & $30.54 \pm 0.23$ & $31.63 \pm 0.15$ & $31.0 \pm 0.63$ & $30.41 \pm 0.43$ & $30.93 \pm 0.57$ \\
\hline WBC $\left(10^{3} / \mathrm{m} \mathrm{m}^{3}\right)$ & $111.46 \pm 0.53$ & $15.93 \pm 0.71$ & $11.80 \pm 1.86$ & 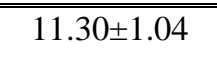 & $12.77 \pm 2.01$ \\
\hline PLT $\left(10^{3} / \mathrm{m} \mathrm{m}^{3}\right)$ & $409.17 \pm 10.74$ & $399.58 \pm 16.99$ & $374.05 \pm 51.58$ & $359.90 \pm 22.14$ & $359.90 \pm 22.14$ \\
\hline
\end{tabular}

Different letters indicate moral differences at ( $\mathrm{P}<0.05)$ row within per recipe

\section{Discussion}

Iron deficiency anemia is the most prevalent nutritional deficiency, not just in the study, but globally, affecting large numbers of children and women in developed countries, as it is the only nutritional deficiency that spreads extensively in industrialized countries [13]. The disease arises when the body's iron stock fails to meet the natural production of red blood cells, insufficient food, poor iron absorption, bleeding, or body iron in deficiency urination [14]. Any defects in the synthesis of heme molecule of hemoglobin molecule, since iron deficiency interferes with heme synthesis which leads to a decrease in the production of hemoglobin and the formation of red blood cells [15].

To care for body iron is maintained by iron balance that carefully regulates to ensure sufficient quantity of pellets absorption to compensate for lost pellets with an estimated loss of iron about 1-2 mg per day, so the body must absorb this quantity 1-2 mg daily to compensate for Internal iron needs which are more than 20-25 $\mathrm{mg}$ as shattered red blood cells at a rate of $0.8 \%$ daily and constantly compensated [14].

Numbers of white blood cells and platelets exceeded natural rates. That iron-deficiency anemia may result due to blood loss that 
results from damage to the digestive or intestinal parasites or bleeding or wounds or inflammation of blood vessels, which leads to iron deficiency and cell coagulation is basic protection mechanism so as to prevent loss of blood from the blood vessels, which leads to increased numbers of platelets and white blood cells as a result of infections associated with blood loss and iron deficiency, since iron deficiency is a contributing factor to increase platelets and white cells [16].

Thalassemia due to defects in Manufacture Alpha or beta chain of hemoglobin which leads to lack of maturation of red blood cells in the bone marrow and leads to the formation of red blood cells which are inefficient and that leads to the analysis and breakdown of cells shortly after bone marrow production which leads to chronic anemia, which affects children at early stages of age causing reduced production of red blood cells and the low level of red blood cells may also be due to changes in the structure and hemoglobin concentration due to the small size and low thickness of mature red blood cells and the lack of beta production chains of hemoglobin, and Clopin excess production of chains Alpha Clopin in patients with Beta-thalassemia lead to the production of abnormal red blood cells (small cell and lack of pigment), abnormal red blood cells produced in the bone marrow and in bone marrow in the initial stages of composition of spleen macrophages by causing Reduced production of red blood cells [17]. The results of the current study are consistent with the findings of the [18] in low hemoglobin concentration in patients with Thalassemia due to the stoppage of Alpha or beta chain manufacturing The increase of number of white blood cells are very common in patients with severe diseases like Thalassemia because of an increase in the number of white blood cells, a sign and latent disorders to aetiology and response that occurs as a result of the reaction of bone marrow for a number of reasons such as bacterial and viral infections, chronic infections, frequent therapy or alfslget operations such as stress suffered by Thalassemia patients due to lack of access of oxygen. Of the tissues, this reaction happens by molecules originating in response to stimulatory events that include alsaitokinat and growth factors (such as granulocyte colony stimulating factor G-CSF and granulocyte macrophage colony stimulating factor GM-CSF) and as a result increase in white blood cells release from storage in the bone marrow Bone [19].

The red blood cells when sickle cell patients contain $80 \%$ of $\mathrm{HbS}$ mean corpuscular hemoglobin, mean corpuscular hemoglobin-containing red cells $\mathrm{HbS}$ oxygen loss is less likely to change their form of natural red blood cells that they decompose, this degradation in cells $r$ arises from losing filamentsof the Membrane oxygen lost during encephalopathy resulting in tmangl cells, which will harden too far in blood vessels and lead to blockage of small blood vessels and cause infarction of tissue, leading to low numbers of red blood cells and 
hemoglobin concentration in blood cells Red [20]. That children with sickle cell anemia may have acquired the splenic blood wetrakd detention and detention of red blood cells in the spleen lead to severe anemia and swelling in the spleen and hypovolemic shock resulting from acute hypovolemic, are particularly vulnerable to sudden and severe infections Some types of bacteria, particularly at ages less than 5 years and the reason might be the shortcomings in virtual functions of the spleen, and as a result the reaction leads to the increase of white blood cells [20].

The red blood cells contain a network of protein microfilaments under the red cell membrane and these strings are attached to the inner surface of the membrane and cellular structure called the red cell membrane, the membrane proteins shortages lead to decouple cellular structure with membrane lipid tier which Ends liberally grease tier shaped bubbles do not contain adipose cell structure, the loss of fat from the membrane to a lack of red cell surface area so the red blood cells, blood cells-baller Methicillin be less amenable to change from normal cells because they are held in the Spleen and thus devoured and destroyed by macrophages in the spleen leading to destruction of red blood cells while normal life causing low numbers of red blood cells and hemoglobin concentration in red blood cells [20]. The detention of the red blood cells of Methicillin and being swallowed it and smashed them continuously in the spleen lead to hyperinflation in spleen deficiency occurs in the spleen functions and as a result may lead to spleen (Splenectomy) leading to increased risk for bacterial infections and inflammations and as a result of that, there happens a reaction that leads to increased numbers of white blood cells [20].

The lack of vitamin B12 spreads significantly among slum dwellers because of malnutrition and inadequate animal food products [21]. The only plant foods during pregnancy and breastfeeding is probably to do with the lack of vitamin B12 in both mother and child because of increased demand for this vitamin [22], as it is as an adjunct $\mathrm{Co}$ factor in Methionine synthase reaction which converts Homosysteine to Methonine, shortage of B12 insurance will raise the level of Homosysteine in serum which is a risk factor for cardiovascular diseases [23]. And Methionine are generators for configuring S-adenosyl methyionine donor of the Methyl and necessary for Methylation of phospholipid [24]. Resampling Ehab Methyl owing to weak DNA, which could contribute to a change in the metabolic pathways for the fetus and increase the risk of chronic diseases in the future. Weak DNA synthesizers also give rise to Megaloblaste anemia characterized by abnormal generating cells of large pellets in bone marrow cells and big red red blood cells Macrocytic Terminal [25].

\section{Conclusion}

1- Low hemoglobin levels in five types of anemia but it was more decrease in the thalassemia, sickle cell and vitamin B12. 
2- Decrease in red blood cell numbers in all kinds of anemia, iron deficiency anemia than thought and balled erythrocytes, the most lack is due to the B12 vitamin deficiency anemia.

3- Note that the mean corpuscular hemoglobin reached its lowest in patients with iron deficiency anemia, while its highest in a B12 vitamin deficiency anemia.

4- A sharp rise in the numbers of white blood cells to exceed the maximum set up in all kinds of anemia, especially in thalassemia with an average more than normal.

5-High numbers of platelets, the deadliest to hit the natural limits on all kinds of anemia, iron deficiency anemia, especially in terms of an average exceeding normal limits

\section{References}

[1] Hoque, M. ; Hoque, E. and kader, S.B. (2009) Risk factors for anemia in pregnancy in rural KwaZulu-Natal, South Africa : Implication for health education and health promotion . SA Fam Pract;51(1):68-72.

[2] Miller, C.J.; Dunn ,E.V.; Berg , B.and Abdouni ,S.F.(2003) A hematological survey of preschool children of the United Arab Emirates. Saudi Med J ; 24(6): 609-13.

[3] Nutrition Research Institute. (1998) food and nutrition in Iraq, p: 1-6.

[4] Luciana , P.; Malaquias , B. ; Pedro, I. and Cabral, J.(2011) Prevalence of anemia and associated factors in children aged 6-59 months in Pernambuco, Northeastern Brazil, Rev Saúde Pública : 45(3).

[5] ACOG (2008) Anemia in pregnancy. American College of Obstetricians and
Gynecologists Practice Bulletin .;112: 2017.

[6] World Health Organization .(2008) Worldwide prevalence of anemia 1993-2005. [7] Gunstream ,S.E.; Benson ,H.J.; Talaro ,A. and Talaro, K.P.(2007) Anatomy and physiology Laboratory Textbook Essentials Version : 144 - 147.

[8] Barbara , J. ; Bain , F.R.A.C.P. F.R.C. (2005) Path Diagnosis from the Blood Smear New England Journal of Medicine ; 353 (5): 498-507.

[9] Duncan, D. B . ( 1955 ) . Multiple range and multiple $\mathrm{F}$ test . Biometrics $11: 1-42$. [10] SAS. 2010. SAS Users Guide: Statistics (Vesion-sed). SAS Inst. Inc. Cary. NC. USA. Ver. 9.1 .

[11] Kern , W.F. ( 2002) Metabolism and Function of Erythrocytes and the Metabolism of Iron In :PDQ hematology , 1 st edition, p 25-48 Philadelphia, USA.

[12] Kamil ,K.H. and Mohammad ,N.S.( 2014) ALaboratory Study of anemia in children aged 6 months to 6 years in erbil city . Medical journal of Babylon; Vol.11No.2 : 274-284.

[13] World Health Organization .(2017) Micronutrient deficiencies . Iron deficiency anemia . www.who,int/ nutrition /topics/ida/en.

[14] Hempel , E.V. and Bollard, E.R. (2016) The Evidence-Based Evaluation of Iron Deficiency Anemia. Med Clin North Am ; 100 (5):1065-75.

[15] Lichtman ,M.A.; Kaushansky ,K.; Kipps ,T.J.; Prchal ,J.T. and Levi ,M.M.(2011) 
Williams Manual of hematology . chapter (9) page (46).

[16] Teofili ,L.; Larocca , L.M.(2011) Advances in understanding the pathogenesis of familial thrombocythaemia . $\mathrm{Br} \mathrm{J}$ Haematol ; 152(6):701-12.

[17] Singer, S.T .; Wu , V . and Mignacca ,R. (2000) Allo- immunization and erythrocyte autoimmunization in transfusion - dependent thalassemia patients of predominantly Asian descent . Blood; 96(10) : $3369-73$.

[18] Bennett , J. and Plum , F . (1996) . Cecil text book of medicine 20th ed. W.B. Saunder comp . Philadelphia : 872 - 879 .

[19] Cotran ,R.S.; Kumar ,V. and Collins ,T.(1999) Robbins Pathologic Basis of Disease. 6th ed. Philadelphia, PA: WB Saunders : 644-96.

[20] Al-Mashhadani, S. A.; quwaiz, L. Abdul-Rahman. (2004) blood diseases. King Saud University. Seventh Edition, p: 63-83.

[21]Allen, L.H.(1994) Vitamin B12 metabolism and status during pregnancy, lactation and infancy. Adv Exp Med Biol ; 352:173-186.

[22] Allen, L.H.(2008) Causes of vitamin B12 and folate deficiency. Food Nutr Bull; 29 (2 Suppl) :S20-34.

[23] Pancharuniti , N.; Lewis, C.A.; Sauberlich ,H.E.; Perkins ,L.L.; Go, R.; Alvarez, J.; Macaluso, M.; Acton ,R.; Copeland ,R. and Cousins ,A.(1994) Plasma homocyst (e) ine, folate, and vitamin B-12 concentrations and risk for early-onset coronary artery disease. The American journal of clinical nutrition ; 59:940-8.

[24] Schwartz , D. E .; Vermeulen , N. M .and O'day , C.L.(2000) S-adenosyl methionine regulation of metabolic pathways and its use in diagnosis and therapy. Google Patents.

[25] Parry, T.(1980) The diagnosis of megaloblastic anaemia . Clinical \& Laboratory Haematology; 2:89-109. 